\title{
Determination of Isoprenaline with Lucigenin Chemiluminescence Using Flow Injection Analysis
}

\author{
Abdulrahman A. Al-Warthan, Saad A. Al-Tamrah and Akel A. Al-Akel \\ Department of Chemistry, College of Science, King Saud University, \\ P.O. Box 2455, Riyadh-11451, Saudi Arabia
}

\begin{abstract}
A procedure is presented for determining isoprenaline $\left(10^{-7}-10^{-4} \mathrm{M}\right)$ in a flow injection system using chemiluminescence detection resulting from the reaction of isoprenaline with $10,10^{\prime}$-dimethyl-9,9'-biacridinium dinitrate (lucigenin) in aqueous solution of potassium hydroxide as a carrier stream. The logarithmic calibration curve was linear over the range from $1 \times 10^{-7} \mathrm{M}$ to $1 \times 10^{-4} \mathrm{M}$. The effects of some analytical conditions on the chemiluminescence yield were investigated. The RSD at $1 \times 10^{-4} \mathrm{M}$ isoprenaline is $0.9 \%$ (10 replicates). The method is directly applicable to aqueous solutions of isoprenaline injection $(1 \mathrm{mg} / 5 \mathrm{ml})$.
\end{abstract}

Keywords Isoprenaline, flow injection analysis, lucigenin chemiluminescence, pharmaceutical preparation

Isoprenaline belongs to an important class of clinical drugs, the catecholamines. Many papers have been published on the determination of catecholamines using batch techniques, such as nonaqueous titrimetry ${ }^{1,2}$, highperformance liquid chromatography (HPLC) with electrochemical $^{3}$ or fluorometric detection ${ }^{4,5}$, radioimmunoassay ${ }^{6}$, spectrophotometry ${ }^{7-10}$, and chemiluminescence. ${ }^{11}$ Flow injection chemiluminescence methods have been shown to be reliable for the determination of trace metal ions and organic compounds with good reproducibility, selectivity and sensitivity..$^{12-14}$

This paper describes a selective and sensitive method for the determination of isoprenaline utilizing lucigenin chemiluminescence (CL) detection. Applications of the method to the determination of the drug in some pharmaceutical preparations are also proposed.

\section{Experimental}

\section{Reagents and chemicals}

Distilled deionized water was used throughout. 10,10'-Dimethyl-9, $9^{\prime}$-biacridinium dinitrate (lucigenin) was purchased from Aldrich, isoprenaline sulfate from Sigma and AnalaR potassium hydroxide from BDH. All chemicals were used as received with no further purification. A stock solution $\left(1 \times 10^{-2} \mathrm{M}\right)$ of isoprenaline sulfate was prepared daily by dissolving $0.2783 \mathrm{~g}$ of pure substance in $50 \mathrm{ml}$ of distilled water. This stock solution was stored in amber-colored bottles in a refrigerator. The lucigenin stock solution ( $1 \times$ $10^{-2} \mathrm{M}$ ) was prepared by dissolving $0.5105 \mathrm{~g}$ of the chemical in $100 \mathrm{ml}$ of distilled water. The base solutions were prepared from potassium hydroxide. Working standard solutions were prepared by appropriate dilution of the stock solutions.

\section{Apparatus}

All (CL) measurements were made on an apparatus which was described previously. ${ }^{14}$

Flow system for the determination of isoprenaline by $C L$

A schematic diagram of the manifold is shown in Fig. 1. An aqueous solution of potassium hydroxide acting as a carrier stream for isoprenaline was supplied through $\mathbf{R}_{1}$ and the lucigenin solution through $\mathbf{R}_{2}$. The drug sample was injected into the alkaline stream from a 50- $\mu$ l Teflon rotary valve injector (Rheodyne RH-5020). The streams were propelled by a four-channel peristaltic pump (Gilson Minipuls 3MP4) and mixed at a PTFE Tpiece before passing to a coiled glass flow cell in front of a photomultiplier tube in the usual way. Both streams

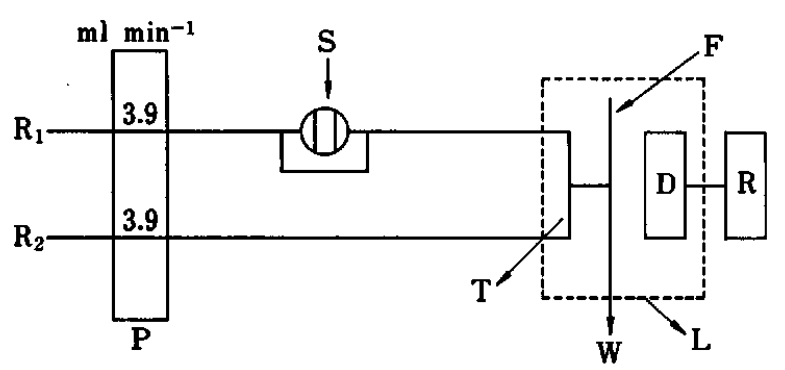

Fig. 1 Manifold used for chemiluminescent determination of isoprenaline: $R_{1}$, carrier stream; $R_{2}$, chemiluminogenic reagent solution; $P$, pump; $S$, injection valve; $W$, waste; $T$, perspex T-piece; F, coiled flow cell; $\mathrm{D}$, detector; $\mathrm{R}$, chart recorder; L, light-tight box. 


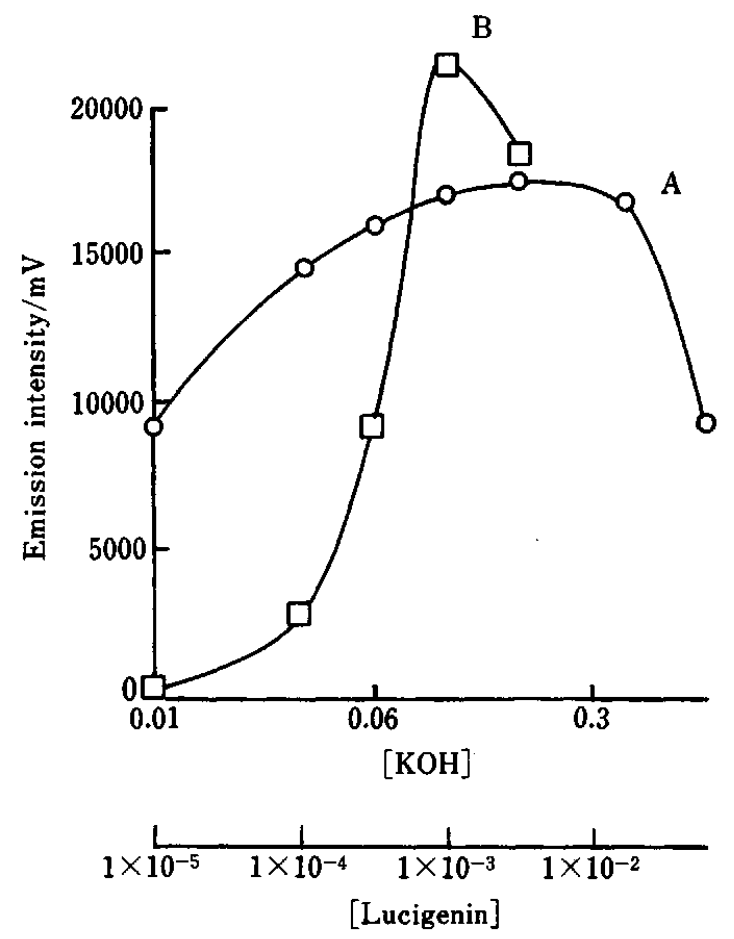

Fig. 2 Variation of chemiluminescence intensity: A, with $\mathrm{KOH}$ concentration in presence of $1 \times 10^{-4} \mathrm{M}$ isoprenaline and $1 \times 10^{-3} \mathrm{M}$ lucigenin; $\mathrm{B}$, with lucigenin concentration in presence of $1 \times 10^{-4} \mathrm{M}$ isoprenaline and $0.1 \mathrm{M} \mathrm{KOH}$.

were pumped at the same flow rate via the Gilson pump (3.9 $\mathrm{ml} \mathrm{min}^{-1}$ in each channel). PTFE tubing $(0.8$ mmi.d.) was used throughout the remainder of the manifold. The light emission was detected by a photomultiplier without wavelength discrimination. The resultant photocurrent was converted to a voltage that was displayed on a chart recorder (Yokogawa Model 3021) and the peak heights were measured manually. All results are the mean of four injections of the sample, unless stated otherwise.

\section{Optimization of the CL flow system}

The optimum reaction conditions for isoprenaline determination were investigated by injecting $50 \mu \mathrm{l}$ of the drug $\left(1 \times 10^{-4} \mathrm{M}\right)$ into the carrier stream with flow rates of $3.9 \mathrm{ml} \mathrm{min}^{-1}$ in each channel. The potassium hydroxide and lucigenin concentrations, the total flow rate and sample volume, all of which affect the intensity of the CL signal, were studied.

\section{Effect of potassium hydroxide concentration}

The dependence of the $\mathrm{CL}$ signal upon $\mathrm{KOH}$ concentration was examined in the range $0.01-0.5 \mathrm{M}$. The results of the $\mathrm{KOH}$ optimization study is shown in Fig. 2A. The chemiluminescent intensity exhibited a maximum at $0.1 \mathrm{M}$, which was selected for the analysis.

\section{Effect of lucigenin concentration}

The parameter next optimized was the lucigenin reagent. The optimization curve for lucigenin con-

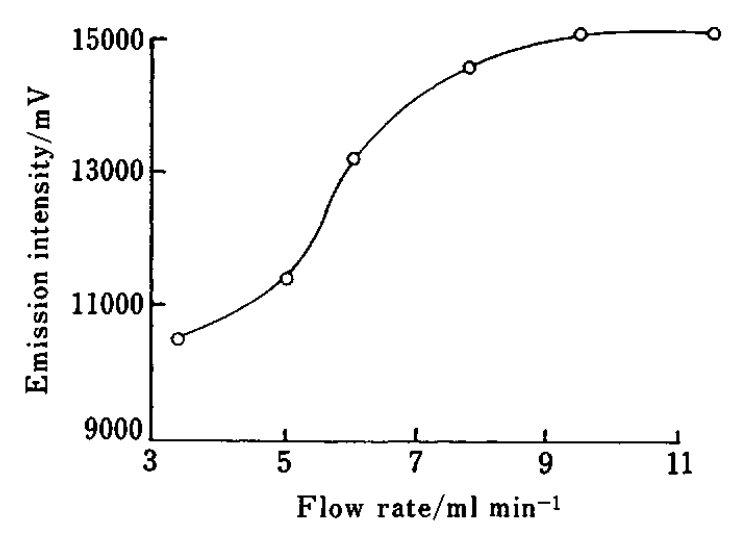

Fig. 3 Effect of total flow rate on chemiluminescence intensity from $1 \times 10^{-4} \mathrm{M}$ isoprenaline, $1 \times 10^{-3} \mathrm{M}$ lucigenin and $0.1 \mathrm{M} \mathrm{KOH}$ solution.

centrations is shown in Fig. 2B. The CL intensity of isoprenaline increased with an increase in the lucigenin concentration. Above $5 \times 10^{-3} \mathrm{M}$ the $\mathrm{CL}$ intensity decreased; this might be due to an increase in intensity of the colored lucigenin solutions which would reduce the emission intensity due to the quenching effect. Thus, the optimum lucigenin concentration for isoprenaline was found to be $1 \times 10^{-3} \mathrm{M}$.

\section{Effect of flow injection variables}

Volume of injected isoprenaline solution. Using a $1 \times$ $10^{-4} \mathrm{M}$ isoprenaline solution and the optimized reagent concentration, the volume of injected isoprenaline was evaluated. The obtained results showed an increase in the emission intensity up to $50 \mu \mathrm{l}$, after which no significant increase was observed. It was therefore decided to continue the experimental optimization using this volume.

Effect of flow rates. The effect of the flow rate on the CL signal was studied. The results obtained are shown in Fig. 3, and indicate that a sufficiently high flow rate should be used to enable the excited product to reach the detector in a minimum time; hence maximum collection of the emitted light can be achieved. In this instance, the intensity increased with increasing flow rate. As the total flow rate was increased from 3.4 to $11.5 \mathrm{ml} \mathrm{min}^{-1}$, the emission intensity also increased. At flow rates higher than $7.8 \mathrm{ml} \mathrm{min}^{-1}$, no significant increase in the emission intensity was obtained and therefore a flow rate of $7.8 \mathrm{ml} \mathrm{min}^{-1}$ was adopted for isoprenaline determination.

\section{Results and Discussion}

\section{Analytical performance}

Under the above-mentioned optimized experimental conditions, a log-log calibration graph for isoprenaline determination was constructed over the range $1 \times 10^{-7}$ $1 \times 10^{-2} \mathrm{M}$. The linear dynamic range was over three orders of magnitude between $1 \times 10^{-7} \mathrm{M}$ and $1 \times 10^{-4} \mathrm{M}$. 
Table 1 Effect of potential interferences (all $1 \times 10^{-3} \mathrm{M}$ ) on the signal for $1 \times 10^{-4} \mathrm{M}$ isoprenaline

\begin{tabular}{lrr}
\hline \multirow{2}{*}{ Interferent } & \multicolumn{2}{c}{ Signal height } \\
\cline { 2 - 3 } & $\mathrm{mV}^{\mathrm{a}}$ & \multicolumn{1}{c}{$\%^{\mathrm{b}}$} \\
\hline & 20800 & 100 \\
$\mathrm{Ca}\left(\mathrm{NO}_{3}\right)_{2} \cdot 4 \mathrm{H}_{2} \mathrm{O}$ & 14300 & 68.80 \\
$\mathrm{CdCl}{ }_{2} \cdot \mathrm{H}_{2} \mathrm{O}$ & 11300 & 54.33 \\
$\mathrm{Co}\left(\mathrm{NO}_{3}\right)_{2} \cdot 6 \mathrm{H}_{2} \mathrm{O}$ & 330 & 1.60 \\
$\mathrm{Mg}\left(\mathrm{NO}_{3}\right)_{2} \cdot 6 \mathrm{H}_{2} \mathrm{O}$ & 18300 & 87.98 \\
$\mathrm{Ni}\left(\mathrm{NO}_{3}\right)_{2} \cdot 6 \mathrm{H}_{2} \mathrm{O}$ & 8600 & 41.35 \\
$\mathrm{~Pb}\left(\mathrm{NO}_{3}\right)_{2}$ & 5100 & 24.52 \\
$\mathrm{NH}_{4} \mathrm{VO}_{3}$ & 6200 & 29.81 \\
$\mathrm{ZnCl}$ & 13500 & 64.90 \\
$\mathrm{HgCl}$ & 5500 & 26.44 \\
$\mathrm{CuCl}$ & 7 & 0.03 \\
Fructose & 19400 & 93.27 \\
Glucose $_{\text {Nicotinamide }}$ & 19200 & 92.31 \\
Carbowax & 19300 & 92.79 \\
Riboflavin & 19300 & 92.79 \\
Mg stearate & 16300 & 78.37 \\
\hline
\end{tabular}

a. Results based on four injections per sample.

b. Relative to isoprenaline solution $=100 \%$.

c. $[$ Carbowax $]=1 \times 10^{-4} \mathrm{M}$; [isoprenaline $]=1 \times 10^{-5} \mathrm{M}$.

d. $[\mathrm{Mg}$ stearate $]=5 \times 10^{-4} \mathrm{M}$; [isoprenaline $]=5 \times 10^{-5} \mathrm{M}$.

The linear range allows the determination of $1 \times 10^{-7} \mathrm{M}$ levels of isoprenaline as a limit of detection ( $2 \times$ blank standrd deviation). The relative standard deviation (RSD) is $0.9 \%$ for $1 \times 10^{-4} \mathrm{M}$ isoprenaline solution (10 replicate injections).

\section{Interferences}

The chemiluminescent reaction apparent from the isoprenaline-lucigenin system is certainly of analytical value. Therefore, the specificity of the method for isoprenaline in the presence of frequently encountered excipients and some inorganic ions was studied. The results obtained are summarized in Table 1 .

Among the potential interferents, $\mathrm{Ca}^{2+}, \mathrm{Cd}^{2+}, \mathrm{Co}^{2+}$, $\mathrm{Ni}^{2+}, \mathrm{Pb}^{2+}, \mathrm{V}^{5+}, \mathrm{Zn}^{2+}, \mathrm{Hg}^{2+}, \mathrm{Cu}^{2+}, \mathrm{Mg}^{2+}$, riboflavin and magnesium stearate interfered severely in the determination by decreasing the emission intensity. Nicotinamide and carbowax also affected the signal response, but their effects were mild compared with those abovementioned interferents. Fructose and glucose did
Table 2 Determination of isoprenaline in a pharmaceutical preparation by the proposed method

\begin{tabular}{|c|c|c|c|}
\hline \multirow{2}{*}{ Preparation } & \multicolumn{2}{|c|}{ Amount of isoprenaline/ $\mathbf{M}$} & \multirow{2}{*}{ Recovery, \% } \\
\hline & Claimed & Found $^{a}$ & \\
\hline \multicolumn{4}{|c|}{ Isoprenaline injection $(1 \mathrm{mg} / 5 \mathrm{ml})$ (Elkins-Sinn) } \\
\hline Sample 1 & $1 \times 10^{-6}$ & $1 \times 10^{-6}$ & 100 \\
\hline Sample 2 & $1.5 \times 10^{-6}$ & $1.5 \times 10^{-6}$ & 100 \\
\hline Sample 3 & $2 \times 10^{-6}$ & $2.05 \times 10^{-6}$ & 102.5 \\
\hline
\end{tabular}

a. Average of four determinations per sample.

interfere, as was confirmed by other workers. ${ }^{15-17}$ These results suggested the possibility of using lucigenin reaction to develope CL methods of analysis for such compounds. However, the interference from these species, namely, the inorganic ions can be obviated by using $1 \times 10^{-2} \mathrm{M}$ EDTA as a masking agent.

Since the reaction does not differentiate between these compounds, the analysis would be most direct if the analytes were separated from each other. Thus, a major strength of this $C L$ reaction could lie in its application as a detector for HPLC.

\section{Analysis of pharmaceutical preparations}

The method was evaluated by determining isoprenaline in a sample of isoprenaline injection (ElkinsSinn, NJ), which contained $c a .1 \mathrm{mg}$ of isoprenaline hydrochloride per $5 \mathrm{ml}$. The results obtained are summarized in Table 2; most of them agreed with reported values.

It is considered of interest to compare the figures of merit for this proposed procedure with those of another spectrophotometric assay for catecholamines, reported by Salem. ${ }^{10}$ Salem's method involves reacting the catecholamine drug (dissolved in acetic acid) with $o$ phenylenediamine dihydrochloride reagent in phosphate buffer medium. The absorbance of the orange color produced was measured at $490 \mathrm{~nm}$ within 20 min against a blank prepared similarly, but omitting the active ingredients.

Statistical analysis of the results reveals that there is no significant difference between them, as shown in Table 3 .

In conclusion, the best sensitivity of the $C L$ reaction of lucigenin with isoprenaline is achieved by using an alkaline medium of potassium hydroxide without any

Table 3 Determination of isoprenaline in a commercial formulation as an injection by the CL and Salem ${ }^{10}$ methods

\begin{tabular}{|c|c|c|c|c|c|}
\hline \multirow{2}{*}{ Formulation } & \multicolumn{3}{|c|}{ Amount of isoprenaline $/ \mu \mathrm{g} \mathrm{m}^{-1}$} & \multicolumn{2}{|c|}{ Recovery \pm S.D., $\%$} \\
\hline & Claimed & $\mathrm{CL}^{\mathrm{a}}$ & Salem $^{\mathbf{a}}$ & $\mathbf{C L}$ & Salem \\
\hline \multicolumn{6}{|c|}{ Isoprenaline injection ( $1 \mathrm{mg} / 5 \mathrm{ml})$ (Elkins-Sinn) } \\
\hline Sample 1 & 1.4 & 1.4 & 1.4 & $100 \pm 0.35$ & $100 \pm 0.77$ \\
\hline Sample 2 & 3.45 & 3.42 & 3.38 & $99.1 \pm 0.90$ & $98.0 \pm 0.86$ \\
\hline Sample 3 & 1.11 & 1.14 & 1.16 & $102.7 \pm 0.15$ & $104.5 \pm 0.45$ \\
\hline
\end{tabular}

a. Average of five determinations per sample. 
oxidizing agent (i.e. $\mathrm{H}_{2} \mathrm{O}_{2}, \mathrm{KMnO}_{4}, \mathrm{OCl}^{-}, \mathrm{BrO}_{3}^{-}$-..etc.). The results obtained are sufficiently sensitive to be used for postcolumn detection of isoprenaline after HPLC separation and could thus be applied to the detection of traces of isoprenaline in body fluids.

\section{References}

1. D. Amin, Analyst [London], 111, 255 (1986).

2. British Pharmacopeia, Her Majesty's Stationery Office, London, 1980.

3. P. T. Kissinger, R. M. Riggin, R. L. Alcorn and L. D. Rau, Biomed. Med., 13, 299 (1975).

4. A. Mitsui, H. Nohta and Y. Ohkura, J. Chromatogr., 344, 61 (1985).

5. A. Yamatodani and H. Wada, Clin. Chem., 27, 1983 (1981).

6. L. J. Riceberg, H. V. Vunakis and L. Levin, Anal. Biochem., 60, 551 (1974).
7. M. E. El-Kommos, Analyst [London], 108, 380 (1983).

8. F. B. Salem and M. I. Walash, Analyst [London], 110, 1125 (1985).

9. M. E. El-Kommos, F. A. Mohamed and A. S. Khedr, $J$. Assoc. Off. Anal. Chem., 73, 516 (1990).

10. F. B. Salem, Anal. Lett., 26, 281 (1993).

11. T. Kamidate, K. Yoshida, T. Kaneyasu, T. Segawa and H. Watanabe, Anal. Sci, 6, 645 (1990).

12. A. A. Alwarthan and A. Townshend, Anal. Chim. Acta, 185, 329 (1986).

13. A. A. Alwarthan, K. A. J. Habib and A. Townshend, Fresenius' Z. Anal. Chem., 337, 848 (1990).

14. A. A. Alwarthan, Analyst [London], 118, 639 (1993).

15. R. L. Veazey and T. A. Nieman, J. Chromatogr., 200, 153 (1980).

16. L. L. Klopf and T. A. Nieman, Anal. Chem., 57, 46(1985).

17. M. Maeda and A. Tsuji, J. Chromatogr., 352, 213 (1986).

(Received October 4, 1993) (Accepted February 25, 1994) 